\title{
An Experimental Investigation on the Mechanical Properties of Gangue Concrete as a Roadside Support Body Material for Backfilling Gob-Side Entry Retaining
}

\author{
Peng Gong $\mathbb{D}^{1},{ }^{1}$ Zhanguo Ma $\mathbb{D}^{1},{ }^{1}$ Xiaoyan $N i \mathbb{D}^{1},{ }^{1}$ and Ray Ruichong Zhang ${ }^{2}$ \\ ${ }^{1}$ State Key Laboratory for Geomechanics and Deep Underground Engineering, School of Mechanics and Civil Engineering, China \\ University of Mining and Technology, Xuzhou, Jiangsu 221116, China \\ ${ }^{2}$ Department of Mechanical Engineering, Colorado School of Mines, Golden, CO 80401, USA
}

Correspondence should be addressed to Zhanguo Ma; zgma@cumt.edu.cn

Received 27 August 2017; Accepted 15 November 2017; Published 17 January 2018

Academic Editor: Peter Majewski

Copyright (c) 2018 Peng Gong et al. This is an open access article distributed under the Creative Commons Attribution License, which permits unrestricted use, distribution, and reproduction in any medium, provided the original work is properly cited.

Development of a safe and economical roadside support body (RSB) material is the key to successful backfilling gob-side entry retaining (GER). By means of laboratory tests, this paper studied the effects of the water-cement ratio, aggregate content, and age on the contractibility and resistance increasing speed, compressive strength, and postpeak carrying capacity of the concrete with gangues as an aggregate. It also discussed the rationality and adaptability of gangue concrete as a RSB material for backfilling GER. The experimental results show that the compressive strength of gangue concrete increases with age, and that the strength of gangue concrete demonstrates a nonlinear decreasing trend with the increase of the cementing material's water-cement ratio. The watercement ratio in the range of $0.46-0.60$ has the most significant regulation effect on the strength of gangue concrete. Mixing with a certain amount of coal gangue enhances the postpeak carrying capacity of concrete, preventing the sample from impact failure. The field experimental results report that as a RSB material, gangue concrete can meet the design and application requirements of GER with gangue backfilling mining. A RSB material featuring high safety, high waste utilization rate, fast construction speed, and low costs is provided.

\section{Introduction}

The gangue backfilling GER (Figure 1(b)) is an innovative mining technology based on gob-backfilled adaptive to multiple complex mining geological conditions without a coal pillar [1]. Based on the present theoretical and technological research on GER in thin and medium thick coal seams under simple conditions, we basically mastered the mine pressure law of the GER with roof caving (Figure 1(a)). In addition, applications under single complex mining geological condition, such as deep mine or the working faces of fully mechanized top coal caving, were explored [2-4]. But to date, GER for working faces with high mining height is still faced with difficulties under deep, heavily stressed, and multiple complex geological conditions, limiting the GER technology development [5]. Since the RSB generally needs to withstand a high vertical stress in the GER process in which roofs are managed using the caving method, the hanging roof at gob side is sheared down to reduce additional load, ensuring the late-stage movement stability of the roof [6-8]. However, under multiple complex geological conditions, the mechanical properties of the traditional RSB materials cannot adapt to the roadway pressure and deformation under the influence of mining, which results in a high supporting cost and a lower entry retaining success rate.

In recent years, as a safe, environmentally friendly mining method, gob-backfilled mining has been applied in China's eastern and central regions. Many scholars have conducted creative research on backfilling mining [9-12], the results of which show that it can reduce the working face pressure and avoid main roof breaking [13-16]. The combination of the backfilling mining technology and the GER technology enables mining without using a coal pillar under multiple complex geological conditions. Because of differences in roof 


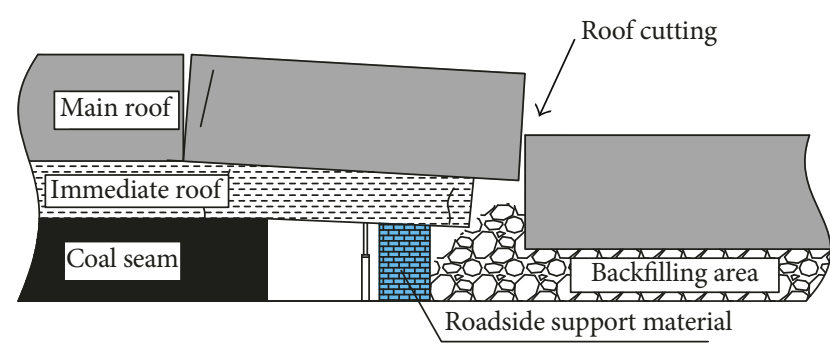

(a)

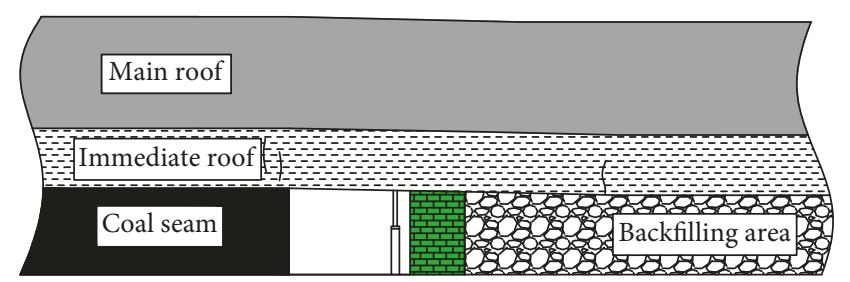

(b)

FIGURE 1: GER of gob roof managed by different methods. (a) GER with roof managed by caving method. (b) GER with roof managed by backfilling method.

"large structure" and the roadside support principle [17-19], there are significant differences in roadside support material requirements between the GER with fully mechanized gangue backfilling mining and the GER in which roofs are managed using the caving method. Consequently, the key to the gangue backfilling GER lies in the development of a safe and economical RSB material which is adaptable to the law of mine pressure in the gob-backfilled GER process.

In the GER development, a variety of RSB materials have been tried by engineers and scholars to maintain roadway stability, such as timber cribs, dense pillar, gangue piling, and masonry walls $[20,21]$. However, due to issues including low support force, large deformation, poor gob isolation, and poor roof connection, the GER stability and safety have been greatly affected. The high water-material backfilling technology that came out in recent years has been applied in GER engineering in which roofs are managed using the caving method, but the high costs limit its application on backfilling GER working faces. However, for working faces with gangue backfilling, in case a large amount of granular gangues can be used as the aggregate to produce the RSB material in entry retaining, then the conveying and backfilling systems can be shared, greatly reducing the roadside support costs, which is favorable to the promotion of the backfilling GER. At the same time, the use of gangues as a RSB material can help remove gangues on the ground, turning the waste into a benefit as well as alleviating the ground environmental problems [22-24].

Coal gangue is a concrete material utilizing gangues as a coarse aggregate and cement as a cementing material, mixed with a certain amount of additives. Recently, scholars have studied the performance of gangue concrete for different application fields: Wang et al. [25] predominately discussed the permeability of the concretes composed of coal gangue and fly ash when applied in farmland drainage ditches. The results indicate that the concrete using waste coal gangue and fly ash had better water permeability than ordinary concrete. And it had a high subsurface drainage modulus, making it feasible for application in coal mining subsidence areas with high groundwater levels. Li et al. [26] developed finite element analysis models of rebar-penetrated connection between gangue concrete filled steel tubular column and reinforced gangue concrete beam using software ABAQUS 6.10 and revealed cyclic behavior of rebar-penetrated connection between gangue concrete filled steel tubular column and reinforced gangue concrete beam. Wu et al. [27] designed a numerical model to predict the development of suction in a cemented gangue backfill mixture containing fly ash.

Through laboratory tests, this paper focuses on the study of the influence of the water-cement ratio, aggregate content, and age on the early stage contractibility and the transitional stage resistance increasing speed, the late-stage compressive strength, and the postpeak carrying capacity of gangue concrete. Through this process, the sensitive control ranges of the various factors affecting gangue concrete performance were obtained. The adaptability of gangue concrete as a RSB material was discussed by taking into account the behavior law of mine pressure of GER with fully mechanized gangue backfilling mining. Based on the analysis of the test results, field tests were carried out in China's Shandong mining area, the results of which suggest that the gangue concrete material designed according to the ratio obtained in this paper can meet the RSB load-deformation requirements in different stages during the entire backfilling GER process. A safe, environmentally friendly and economical RSB material is provided for the development and promotion of GER with fully mechanized gangue backfilling mining.

\section{Test Method and Scheme Design}

2.1. Test Materials. Cement clinker (p.c32.5) was used, and granular gangues of $0-25 \mathrm{~mm}$ in diameter were used as the aggregate in the test. Considering the economy and rationality of GER engineering, the gangues were obtained directly from the gangue piles in the experimental mining area. In order to give a reasonable explanation of gangue concrete strength evolution, the particle size distribution and mechanical properties of the aggregate were measured first.

(1) Particle size distribution characteristics of crushed gangues

The initial crushed gangue particles obtained from the field are continuously graded granular materials. A Talbot formula was used to quantitatively describe the particle size distribution characteristics of gangues:

$$
P_{x}=100\left[\frac{d}{D}\right]^{n}(\%),
$$

where $P_{x}$ is the passing percentage of the $d$ aggregate, $D$ is the maximum particle size of the granular gangues, $d$ is the 

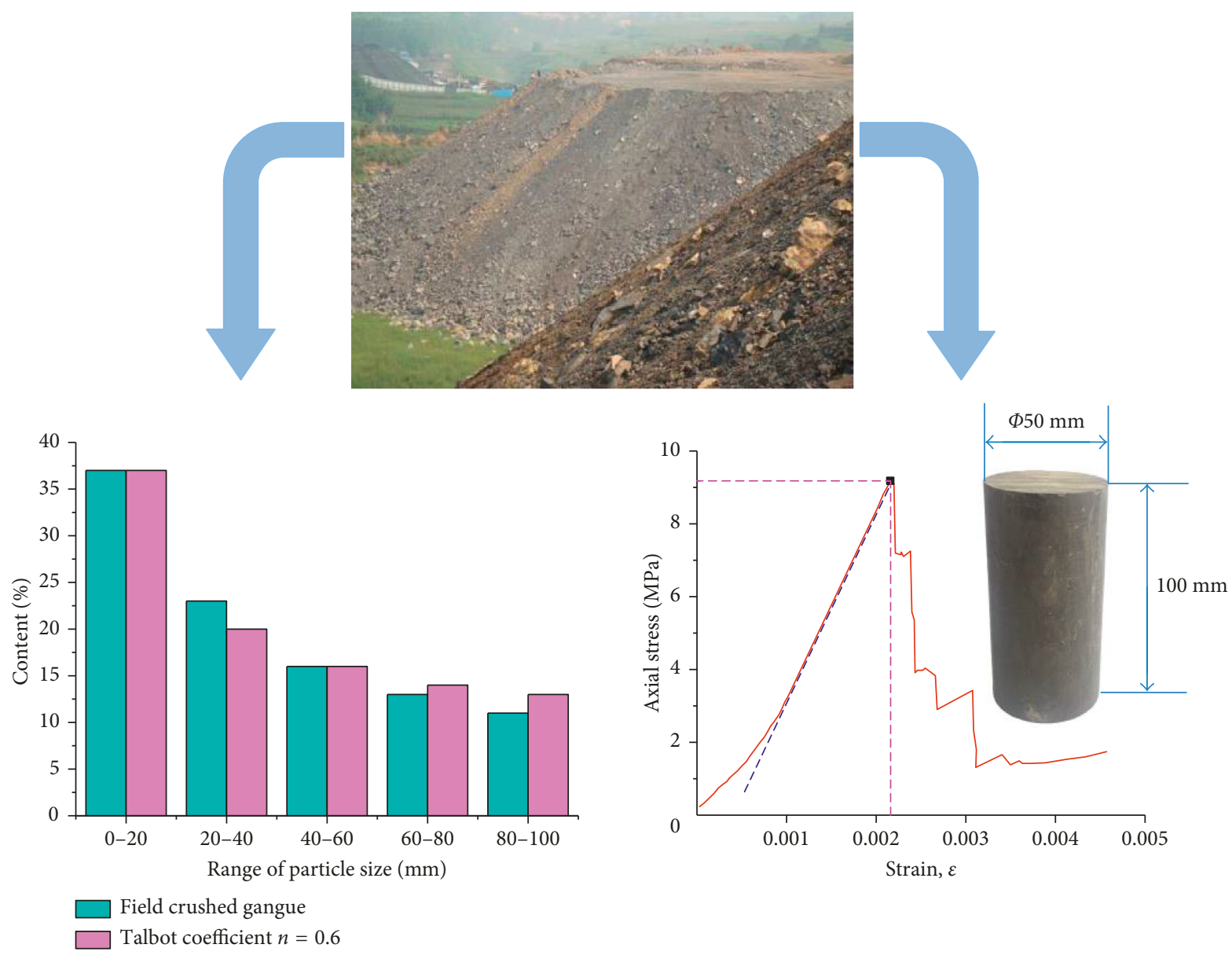

FIgURE 2: Gangue strength and particle size distribution.

current size of the granular gangues, and $n$ is the coefficient of the Talbot formula.

The analysis results show that the aggregate basically satisfies the continuously graded distribution characteristics with a Talbot coefficient $(n=0.6)$. Figure 2 shows the comparison of the particle size distribution characteristics between the gangue aggregate and when $n=0.6$.

(2) Mechanical properties of the complete gangue samples

To obtain the strength characteristics of the gangue aggregate for analyzing the coordination mechanism of the aggregate and the cementing material, uniaxial compression tests were carried out on multiple complete gangue samples $(\Phi 50 \mathrm{~mm} \times 100 \mathrm{~mm})$ in this paper, and the average unconfined uniaxial compressive strength obtained is $9.83 \mathrm{MPa}$. The compressive strength results of the standard gangue samples are shown in Table 1. From the uniaxial compression characteristic curve of gangues shown in Figure 2, it can be seen that the gangues have a certain postpeak carrying capacity. Moreover, a number of shear cracks occur during the crushing process, suggesting that the gangues had piled in the open air and experienced long-term weathering and soaking. Their initial fissures are relatively developed, and the strength of the granular gangue aggregate is lower than the ordinary concrete aggregate.

2.2. Test System and Sample Preparation. Samples were prepared according to the concrete sample forming and curing standards with a design size of $150 \mathrm{~mm} \times 150 \mathrm{~mm} \times 150 \mathrm{~mm}$. To guarantee the reliability of the data, 3 samples were prepared for the same ratio and age. The test used the MTS 816 test system (Figure 3 ) that ensures highly accurate and high sensitivity results.

2.3. Experimental Scheme Design. Walker et al. [28] found that the concrete strength is mainly determined by the following factors: (1) the strength of the cement matrix; (2) the bonding strength of the mortar and the coarse aggregate; (3) the strength, stiffness, and grading of the coarse aggregate; and (4) the maximum size of the aggregate particles. After determining the strength, stiffness, grading, and the maximum size of the coarse aggregate in the field, the test used the orthogonal test design method (Table 2) to design pure cement (nonaggregate) samples with a same watercement ratio for each gangue concrete group to provide a comparison. The following factors influencing gangue concrete properties were mainly considered: 
TABLE 1: Unconfined uniaxial compression test results for the standard cylindrical gangue samples.

\begin{tabular}{lccccc}
\hline \multirow{2}{*}{ Gangue no. } & \multicolumn{2}{c}{ Sample size $(\mathrm{mm})$} & Compressive strength $(\mathrm{MPa})$ & Elastic modulus $(\mathrm{GPa})$ & Poisson's ratio \\
& Diameter & Height & 9.17 & 5.11 & 0.21 \\
G-01 & 49.8 & 98.3 & 10.33 & 4.32 & 0.22 \\
G-02 & 49.8 & 97.7 & 7.32 & 4.83 & 0.18 \\
G-03 & 49.9 & 102.3 & 11.82 & 5.08 & 0.22 \\
G-04 & 49.8 & 101.7 & 10.52 & & 0.22 \\
G-05 & 49.9 & 98.6 & & & \\
\hline
\end{tabular}

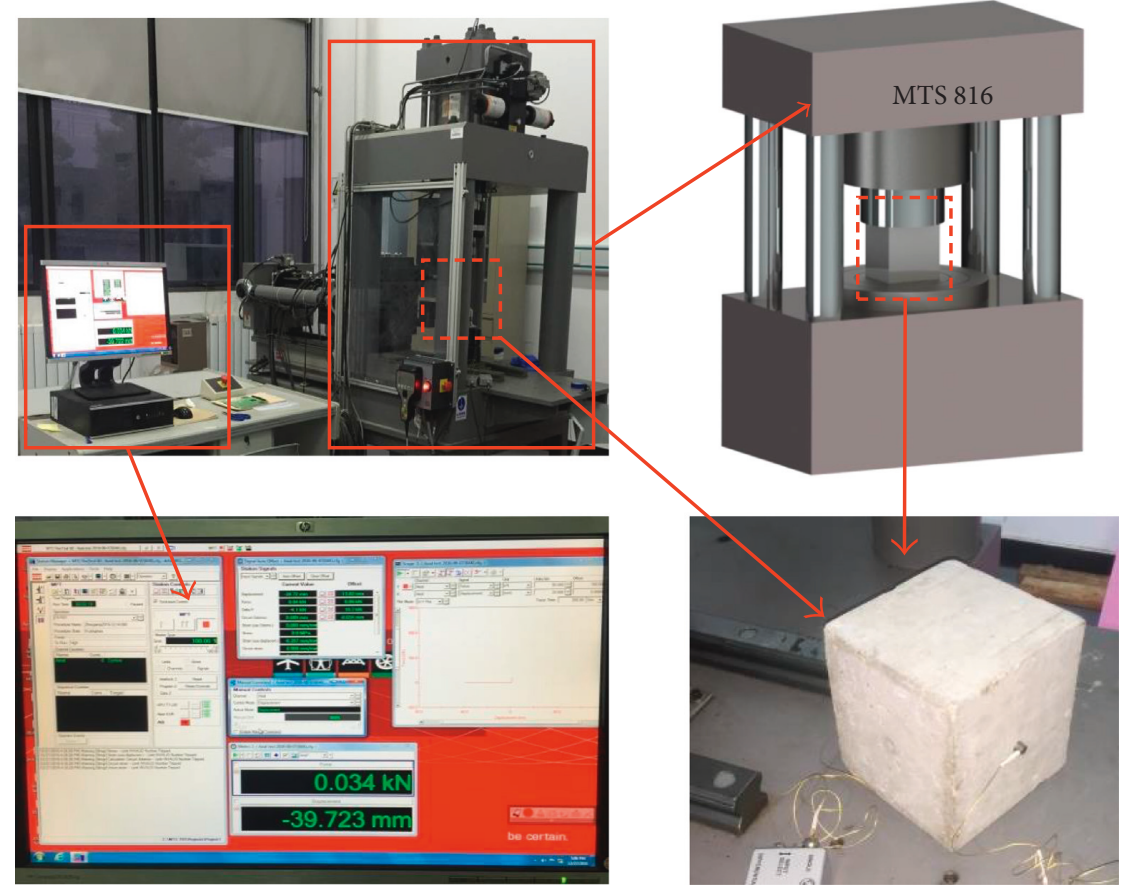

MTS816 servo-control system
Gangue concrete specimen

FIGURE 3: Test system and formed samples.

(1) Water-cement ratio: water-cement ratio is an important factor affecting the strength of the cementing material. The water-cement ratios of $0.40,0.43,0.46$, $0.50,0.55$, and 0.6 were considered in this test.

(2) Aggregate content: four aggregate content levels were considered, respectively, which include $45 \%$, $50 \%, 55 \%$, and $60 \%$.

(3) Curing age: for gangue concrete samples and pure cement samples with each water-cement ratio and gangue content level, three ages were considered, that is, 7 days, 14 days, and 28 days, for studying the evolution rules of the compressive strength properties of gangue concrete in different hardening stages.

\section{Test Results and Discussion}

3.1. Effect of the Water-Cement Ratio on the Mechanical Properties of Gangue Concrete. The average concrete strength with a $50 \%$ gangue content level under different water-cement ratios can be obtained through uniaxial compression tests of the gangue concrete sample groups 1-6, as noted in Figure 4. With the increase of the watercement ratio of the cementing material, the gangue concrete strength demonstrates a nonlinear decreasing trend. When the ratio is greater than 0.46 and less than 0.60 , the gangue concrete strength becomes more sensitive to the ratio. When the ratio is less than 0.46 , the decrease of the ratio has little effect on the late stage strength of the gangue concrete. Within the sensitivity range of the water-cement ratio, the strength of the 28-day gangue concrete is adjustable at 4.97-10.18 $\mathrm{MPa}$.

The average strength of the cementing material under different water-cement ratios can be ascertained through uniaxial compression tests of pure cement sample groups 7-12, as depicted in Figure 5. The raising of the watercement ratio increases the free water in the cementing material during the cement hardening process, and the average compressive strength of the pure cement samples monotonously decreases with the increase of the watercement ratio. 
TABLE 2: Sample gangue concrete ratios (mass ratios).

\begin{tabular}{lccccc}
\hline No. $\begin{array}{c}\text { Gangue } \\
\text { content (\%) }\end{array}$ & $\begin{array}{c}\text { Water- } \\
\text { cement } \\
\text { ratio }\end{array}$ & $\begin{array}{c}\text { Water } \\
\text { content (\%) }\end{array}$ & $\begin{array}{c}\text { Cement } \\
\text { content }(\%)\end{array}$ & $\begin{array}{c}\text { Age } \\
\text { (day) }\end{array}$ \\
\hline 1 & & 0.40 & 14.29 & 35.71 & $7,14,28$ \\
2 & & 0.43 & 15.03 & 34.97 & $7,14,28$ \\
3 & 50 & 0.46 & 15.75 & 34.25 & $7,14,28$ \\
4 & & 0.50 & 16.67 & 33.33 & $7,14,28$ \\
5 & & 0.55 & 17.74 & 32.26 & $7,14,28$ \\
6 & & 0.60 & 18.75 & 31.25 & $7,14,28$ \\
\hline 7 & & 0.40 & 14.29 & 35.71 & $7,14,28$ \\
8 & & 0.43 & 15.03 & 34.97 & $7,14,28$ \\
9 & & 0.46 & 15.75 & 34.25 & $7,14,28$ \\
10 & 0 & 0.50 & 16.67 & 33.33 & $7,14,28$ \\
11 & & 0.55 & 17.74 & 32.26 & $7,14,28$ \\
12 & & 0.60 & 18.75 & 31.25 & $7,14,28$ \\
\hline 13 & 45 & & 14.29 & 35.71 & $7,14,28$ \\
14 & 55 & 0.4 & 14.29 & 35.71 & $7,14,28$ \\
15 & 60 & & 14.29 & 35.71 & $7,14,28$ \\
\hline
\end{tabular}

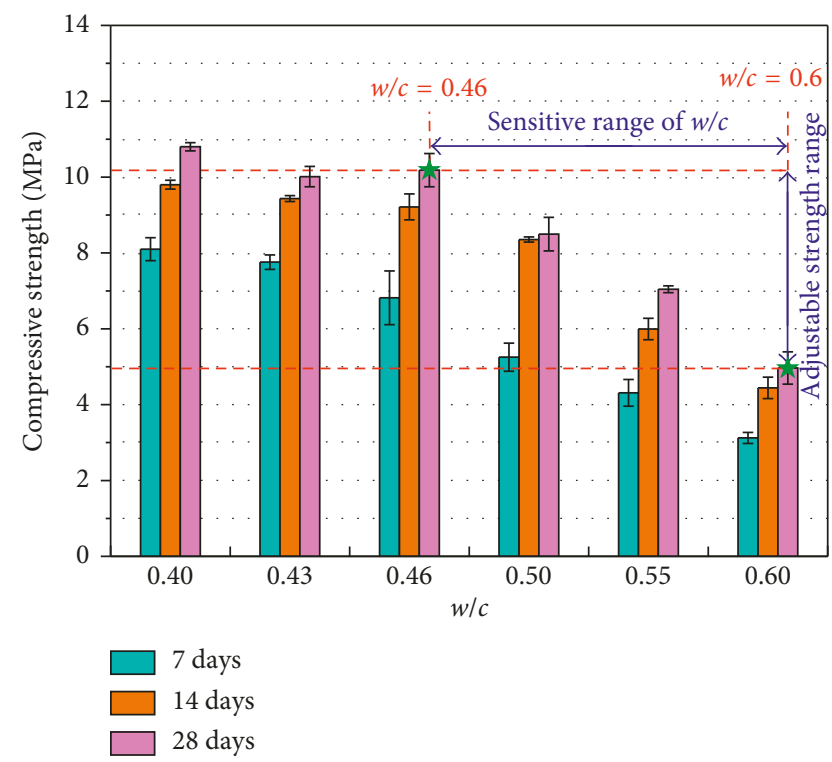

FIgURE 4: Average strength and error of the concrete with different water-cement ratios and a gangue content of $50 \%$.

With a comparison between Figures 4 and 5, it can be assumed that the strength of the gangue concrete is jointly determined by the aggregate, the cementing material, and their bonding surface. Damage and failure are first present in the weakest one of them, resulting in the overall instability of the concrete samples. The strong water absorption of the gangues during the mixing of the concrete mix causes a local low water-cement ratio on the surface of the gangue granules and thus increases the compactness of cement stone near the surface of the gangue aggregate. Concurrently, because the surface of the gangue particles is rough with micropores, the bonding surface between gangues and the cementing material

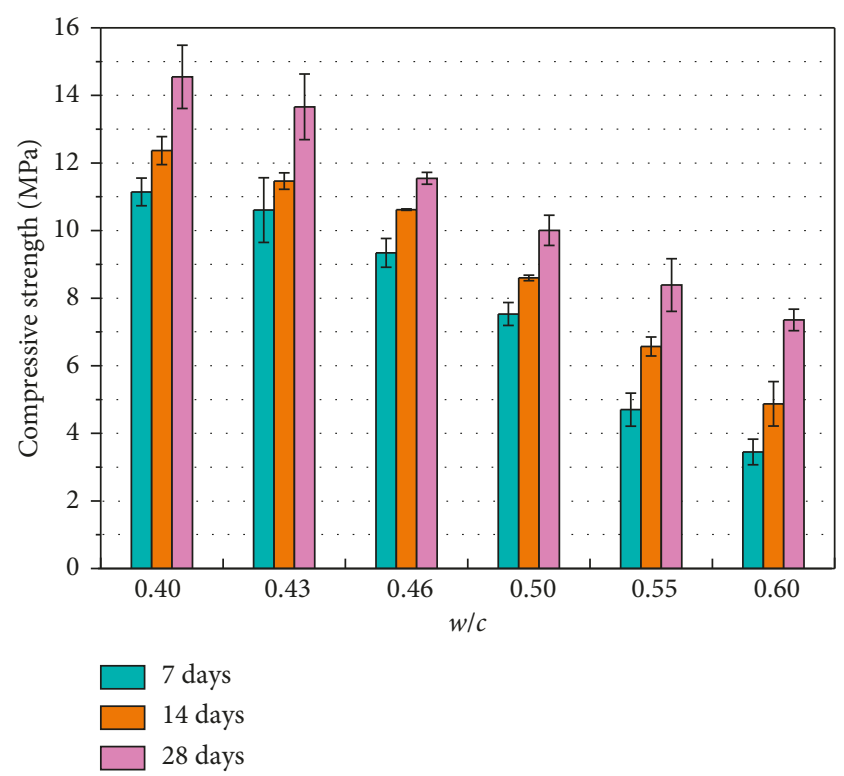

FIGURE 5: Average strength and error of the pure cement samples with different water-cement ratios.

is enlarged, and the binding power between gangues and the cement stone is improved. Hence, the bonding strength at the interface between the aggregate and the cement paste in the gangue concrete is higher than that of the ordinary concrete. When the water-cement ratio lies within the range of $0.46-0.60$, the cementing material's strength in the gangue concrete is lower than the strength of the aggregate. Therefore, the cementing material's strength determines the overall strength of the gangue concrete, and changing the watercement ratio has a relatively significant influence on the gangue concrete's strength. When the water-cement ratio is within the range of $0.40-0.46$, the strength of the cementing material is greater than that of the aggregate. When the vertical stress is greater than $10 \mathrm{MPa}$ during the loading process, damages appear inside the aggregate, eventually leading to the instability of the samples. Therefore, increasing the strength of the cementing material within the above range has no notable effects on the strength of the gangue concrete.

Therefore, within the water-cement ratio range described in this test, to allow a full harmonization between the strengths of the aggregate and the cementing material, it can be expected that the sensitivity range of the water-cement ratio lies in $0.46-0.60$ for controlling the strength of gangue concrete. In the application of backfilling GER engineering, the RSB load requirements may be satisfied plus a full use of the carrying capacity of the granular gangues through adjusting the water-cement ratio of the cementing material within the sensitivity range based on understanding the roof load law and by considering the strength characteristics of gangues.

3.2. Effect of the Aggregate on the Mechanical Properties of Gangue Concrete. The average concrete strength with dissimilar gangue contents can be obtained through uniaxial 


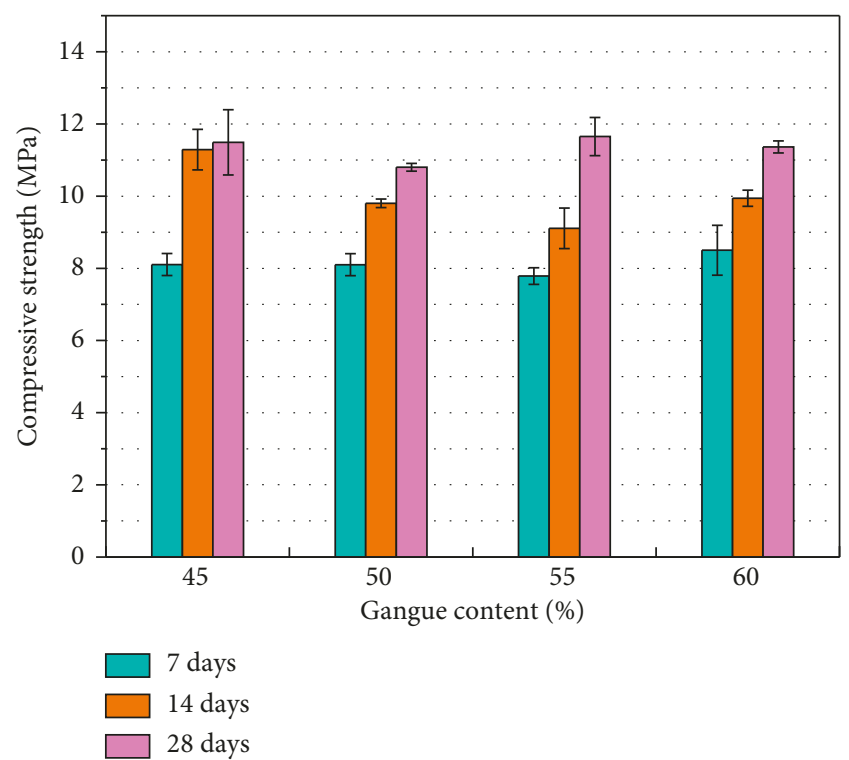

FIGURE 6: Concrete strengths at various ages with different gangue contents.

compression tests of the gangue concrete sample groups $1,13,14$, and 15 , as noted in Figure 6 . It can be seen from the figure that with the gangue content falling in the range of $45 \%$ to $60 \%$, the strength of the gangue concrete with a 28-day age reaches 10.8 to $11.6 \mathrm{MPa}$. Since the granular gangues have many fissures, the strength of the coal gangue aggregate is lower than that of the complete gangue samples. However, the rough and water-absorbing surface of gangues allows both a larger contact area between the aggregate and the cementing material and a reduced local water-cement ratio on the aggregate surface. A hard cement stone shell forms around the gangues, which constrains the lateral deformation of the aggregate. It puts the gangues in a threedimensional stress state in the concrete, improving the ultimate strength of the fractured granular gangues. Therefore, the uniaxial compressive strength of the gangue concrete samples is higher than that of the complete gangue samples. Concurrently, the aggregate's own damage is a key factor leading to the overall concrete destruction.

With the water-cement ratio at 0.40 , the increase of the gangue content has little effect on the concrete strength. Therefore, it can be deduced that when the water-cement ratio and the aggregate strength are kept unchanged, the gangue content within a certain range is not a notable factor affecting the strength of gangue concrete. However, by comparing the uniaxial compression characteristics of the sample groups 7 and 15 (Figure 7), it can be seen that as an aggregate, coal gangue has a vital effect on the destruction mode and the postpeak carrying characteristics of concrete.

As shown in Figure 7, the entire gangue concrete compression process can be divided into three stages according to the destruction characteristics. Stage 1 is the elastic stage, in which the stress and the strain maintain a linear relation following the initial compaction and the elasticity modulus remains constant. There are no obvious cracks on the gangue concrete surface in this stage. Stage 2 is the stiffness attenuation

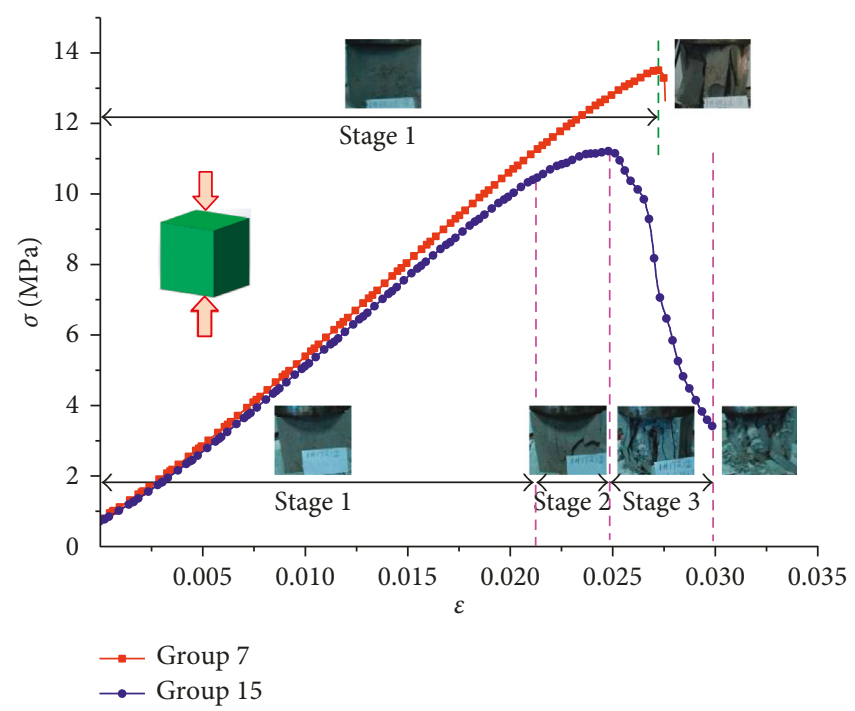

Figure 7: Destruction characteristics of the gangue concrete and the pure cement samples with the same water-cement ratio.

stage, which begins with the appearance of nonlinear stressstrain growth and ends when the peak stress is achieved. With the increase of the strain, the stiffness of the samples is reducing continuously, but the stress is still rising. In this stage, fine cracks appear on the surface of the samples, which gradually evolve into local surface spalling. Stage 3 is the postpeak stage. With the increase of the strain, the stress demonstrates a decreasing trend, and the crack development is relatively slow until finally the samples are destructed due to excessive deformation. The samples have a certain postpeak carrying capacity. Such features allow the adaptability to the large deformation requirement of the RSB and a slow release of the internal elastic energy in the RSB, avoiding the impact damage caused by a sudden release of the internal elastic energy. In the destruction of the nonaggregate samples with the same water-cement ratio, only the characteristics in stage 1 (the elastic phase) are present throughout the compression process, and once at the strength limit, the samples will experience a brittle failure. The destruction is mainly in a form of tensioning and splitting to a relatively great degree of damage with a certain impact. The postpeak carrying capacity of the samples is poor with a small yield. Obviously, in terms of safety and economy, the gangue concrete material mixed with aggregate at a certain proportion has obvious advantages in GER engineering practices.

\subsection{Effect of the Age on the Mechanical Properties of Gangue Concrete}

3.3.1. Effect of the Age on the Strength of Gangue Concrete. The strength limit of the gangue concrete was obtained for various ages with various water-cement ratios and a gangue content of $50 \%$ through uniaxial compression tests of the gangue concrete groups 1 to 6 , which is shown in Figure 8 . Regardless of the water-cement ratio, the compressive strength of the gangue concrete demonstrates an 


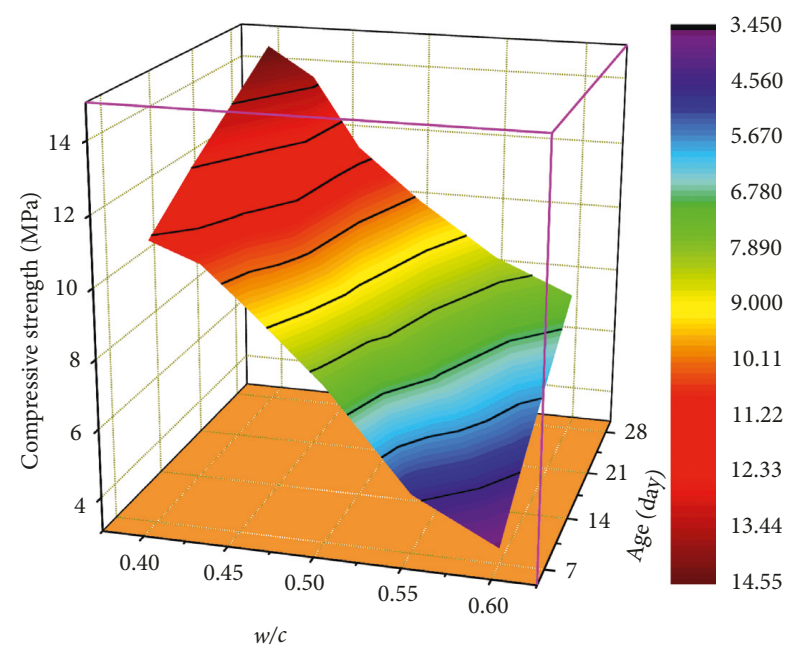

FIGURE 8: Average compressive strength of the gangue concrete at different ages with different water-cement ratios (gangue content: 50\%).

increasing trend with the age. After mixing the coal gangue and cement with water, $\mathrm{Ca}(\mathrm{OH})_{2}$ produced by the hydration of the calcareous material had a secondary reaction with the active $\mathrm{SiO}_{2}$ and $\mathrm{Al}_{2} \mathrm{O}_{3}$ in the coal gangue, forming the stable water-insoluble hydrated calcium silicate gel and hydrated calcium aluminate gel. The cross reaction, joint production, and mutual filling of the secondary hydration products reduce the porosity of the hydration products, increasing the late stage strength.

The field test results show that the working faces of GER with fully mechanized gangue backfilling mining stabilize at the 28-day age after backfilling, and the working load of the RSB is fundamentally stable. Hence, in studying the influence rules of the age on the gangue concrete's strength in gangue backfilling GER engineering, it is necessary to determine whether the 28-day strength of the gangue concrete can meet the working load requirements in the stable period and to analyze whether the development degree of the gangue concrete's early stage strength can satisfy the mininginduced pressure requirements in the GER process. In this paper, the development degree of the gangue concrete's strength is expressed as a percentage of the early age strength of the samples to the strength at the 28-day age:

$$
\begin{aligned}
& f_{7 \mathrm{~d}}=\frac{s_{7 \mathrm{~d}}}{s_{28 \mathrm{~d}}} \times 100 \%, \\
& f_{14 \mathrm{~d}}=\frac{s_{14 \mathrm{~d}}}{s_{28 \mathrm{~d}}} \times 100 \%,
\end{aligned}
$$

where $f_{7 \mathrm{~d}}$ and $f_{14 \mathrm{~d}}$ represent the development degrees of the gangue concrete's strength at the 7-day and 14-day ages, respectively. $s_{7 \mathrm{~d}}, s_{14 \mathrm{~d}}$, and $s_{28 \mathrm{~d}}$ depict the concrete's compressive strengths at the 7-day, 14-day, and 28-day ages, respectively.

Table 3 shows the strength development conditions of the concrete with different water-cement ratios and a gangue content of $50 \%$. Within the range of $0.40-0.60$, the average value of $f_{14 \mathrm{~d}}, 91.37 \%$, for the concrete samples with a gangue content of $50 \%$ is notably higher than that of the pure cement samples which is $81.90 \%$. Their average values of $f_{7 \mathrm{~d}}$ are
TABLE 3: Strength development degree of the early age gangue concrete.

\begin{tabular}{lcccc}
\hline $\begin{array}{l}\text { Water- } \\
\text { cement } \\
\text { ratio }\end{array}$ & $\begin{array}{c}\text { Without } \\
\text { gangue }\end{array}$ & $\begin{array}{c}50 \% \text { gangue } \\
\text { content }\end{array}$ & $\begin{array}{c}\text { Without } \\
\text { gangue }\end{array}$ & $\begin{array}{c}50 \% \text { gangue } \\
\text { content }\end{array}$ \\
\hline 0.40 & 76.60 & 75.00 & 85.01 & 90.74 \\
0.43 & 77.64 & 77.49 & 83.93 & 94.23 \\
0.46 & 80.89 & 66.95 & 91.96 & 90.48 \\
0.50 & 75.27 & 61.81 & 85.94 & 98.32 \\
0.55 & 56.05 & 61.24 & 78.32 & 85.15 \\
0.60 & 46.89 & 62.86 & 66.24 & 89.40 \\
Average & 68.89 & 67.56 & 81.90 & 91.37 \\
\hline
\end{tabular}

essentially the same, which are $67.56 \%$ and $68.89 \%$, respectively. From Figures 4 and 5, it can be seen that the gangue concrete has basically reached its late stage strength at the 14-day age, after which the strength has a very small increase, indicating that with the addition of the gangue aggregate, the concrete's hydration and hardening processes are significantly accelerated.

In a general GER condition, because backfilling measures are not taken for the gob, the roof shearing needs to be done in the initial stage of the roadside support. The field test results show that the roof shearing resistance is commonly required at 3-6 MPa, so the early stage strength of the RSB material is particularly critical. During the roof shearing process, a low strength of the RSB material will lead to insufficient roadside support, excessive roof deformation, and in a serious scenario roof breaking along the solid coal side, resulting in an accident. In the condition of GER with fully mechanized gangue backfilling mining, due to the support of the backfilling area, the gob-side roof subsidence is smaller than in the general GER condition. Moreover, with continuous support, the roof will only bend and subside to a certain degree on the whole without obvious weighting. Therefore, the RSB does not serve as the main carrier of the roof load at the beginning of entry retaining, and so the early stage RSB strength required is smaller than that of GER with roof shearing. It can be seen from Figure 4 that the early average strength of the gangue concrete material with various mixing ratios reaches $3.1-8.1 \mathrm{MPa}$, which is greater than the roof shearing resistance. Therefore, the compressive strength of the material fundamentally meets the early stage vertical load bearing requirements.

Moreover, for solid backfilling GER, it is necessary to guarantee the structural stability of the RSB under the lateral pressure of the granular backfilling material in the gob. Therefore, to ensure that the RSB does not slip toward the inner side of the roadway and loose stability due to rotation, it is required to carry a design load within a reasonable range. The results of the existing practices show that the vertical stress is gradually increasing from the working face to the backfilling area, which essentially stabilizes $30 \mathrm{~m}-50 \mathrm{~m}$ back from the working face (Figure 9). The lateral pressure exerted by the granular material on the RSB is also fundamentally consistent with this trend, mainly because the 


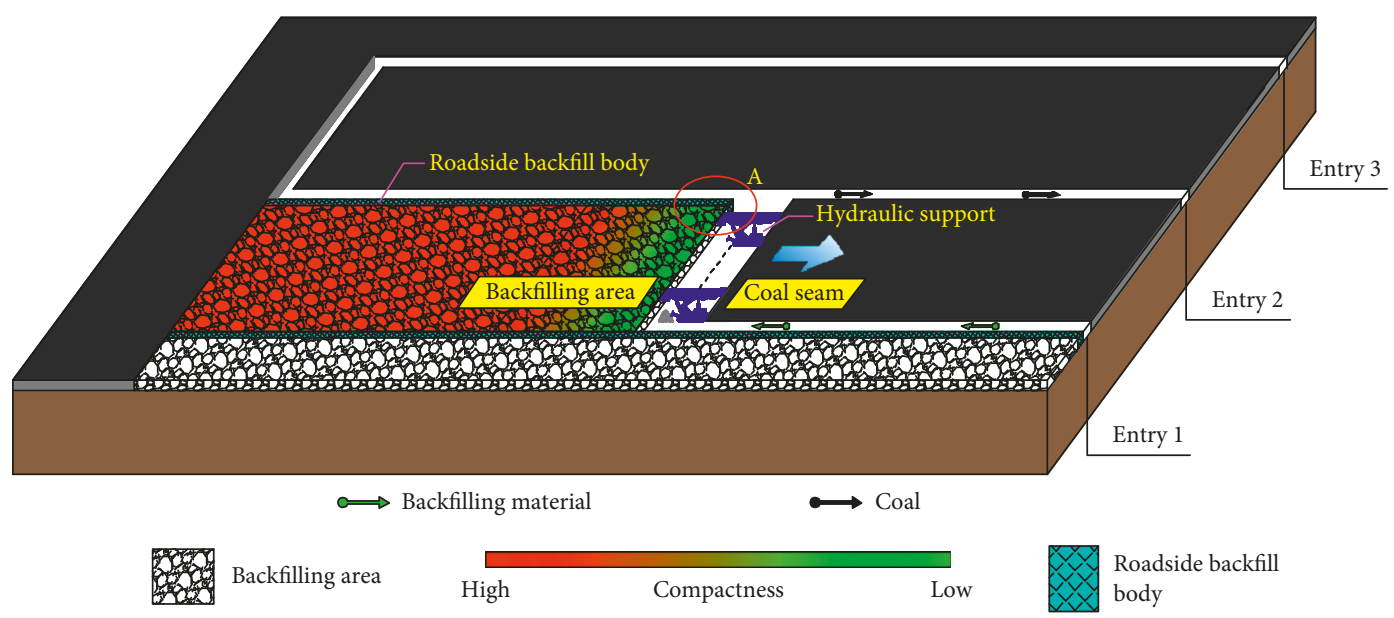

FIgURE 9: Schematic diagram of the vertical stress distribution in the backfilling area.

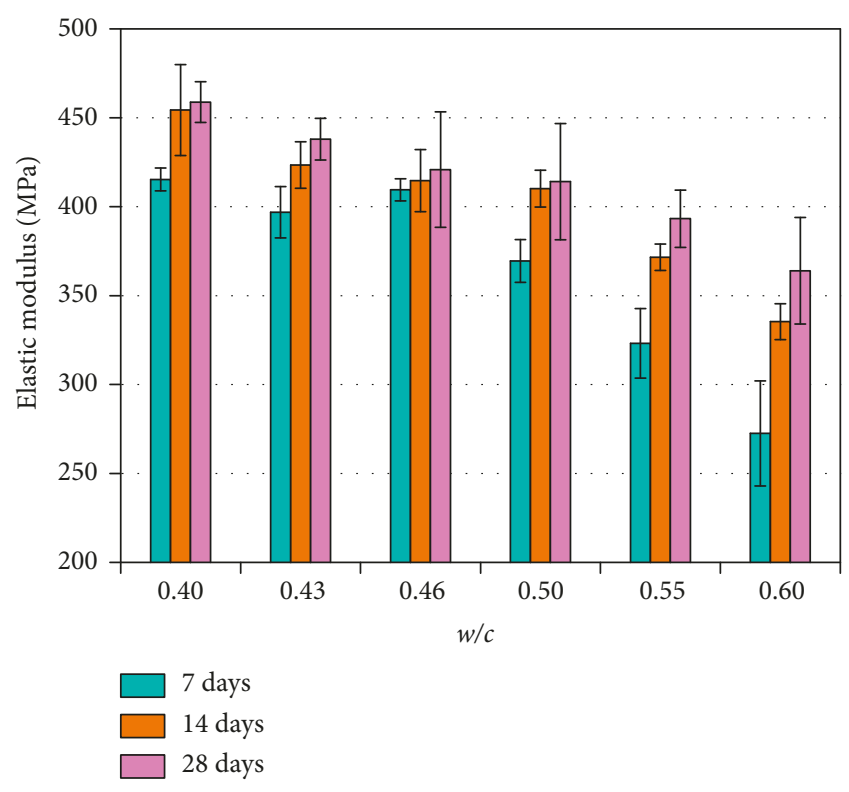

Figure 10: Average elastic modulus and error of the gangue concrete at various ages.

reason that the lateral pressure coefficient of the granular material with a certain property does not change with the vertical stress. Therefore, as a RSB material, gangue concrete is required to have a sufficient compressive strength to withstand a certain vertical load and prevent slippage and side turn under the lateral pressure of the granular backfilling material in the gob, which will affect the safe use of the retained entry. Alternatively, it is required to have a certain degree of contractibility to adapt to the "given deformation" of the roof in the A area when the vertical support is insufficient in the backfilling area in the early stages. In engineering practices, the strength proportion should be chosen in an economical and rational manner according to the above principles while considering parameters, such as the RSB width and aspect ratio and the surface slope angle on the gob side.

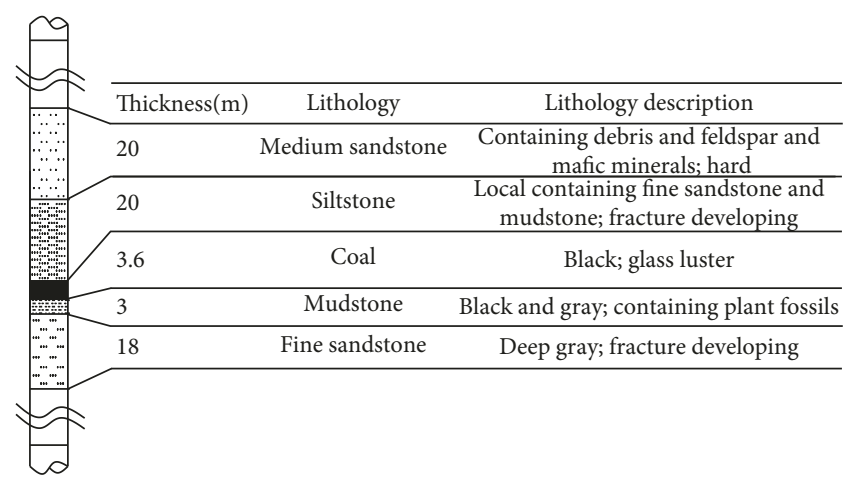

Figure 11: Strata geological log.

\subsubsection{Effect of Age on the Contractibility of the Gangue} Concrete. From the stiffness development with the gangue concrete age as shown in Figure 10, it can be seen that the stiffness of the 7-day gangue concrete is obviously lower than the stiffness of the 14-day gangue concrete. Since cement hydration is related to the age, the increasing trends of the elastic modulus with time are apparent before the 14-day age, and the elastic modulus stabilizes when the age is greater than 14 days. This property can adapt to the early stage deformation of the roof in GER with fully mechanized gangue backfilling mining. In a general GER condition, since the roadside support is a passive support and the roof will produce a certain amount of given deformation, the roof-floor displacement of the roadway accounts for $80 \%$ of the total surrounding rock deformation for the area $20 \mathrm{~m}$ in front of the working face and the area from the back of the backfilling roadside support to $80 \mathrm{~m}$ in back of the working face. In contrast, with the gob backfilling effect, the roof subsidence mainly concentrates $30 \mathrm{~m}$ in back of the working face. So, at age 0-14 days, a relatively high contractibility is required for the roadside support, while in the late stable stage and the second working, a relatively high strength is required. In the initial stage of entry retaining, the roadway support can be adaptable to the given deformation of the roof in 


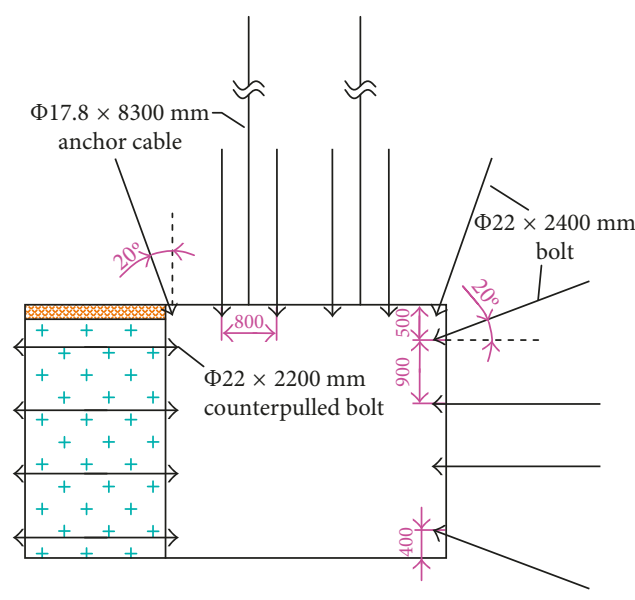

(a)

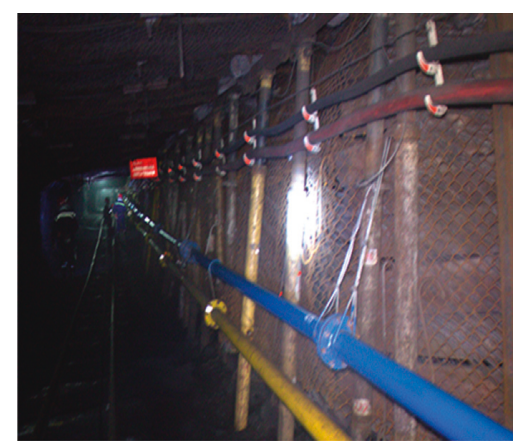

(b)

Figure 12: Roadway support design and effect. (a) Roadside support design scheme. (b) Roadside support effect.

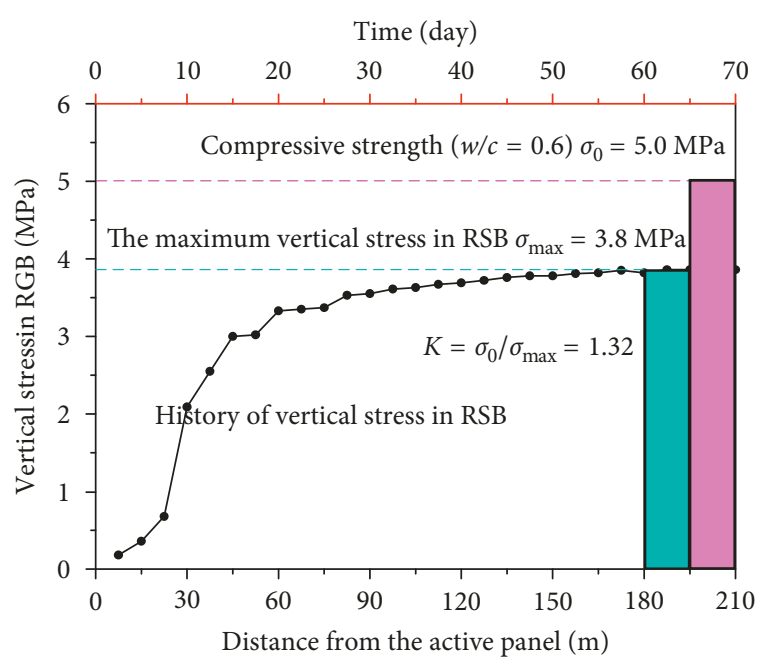

(a)

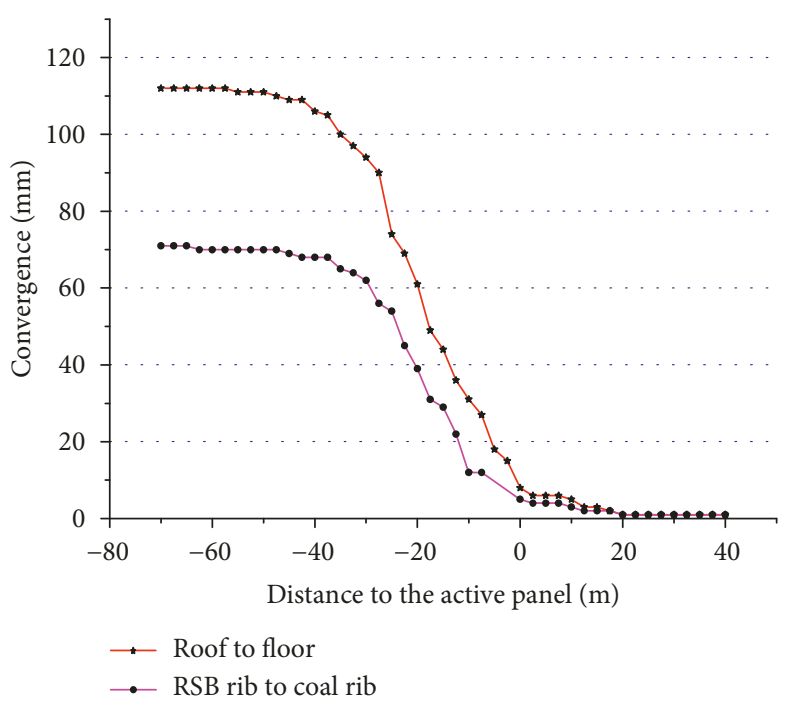

(b)

FIGURE 13: Monitoring result during advancement of the working face. (a) Vertical stress in RSB. (b) Roadway deformation curve.

GER with fully mechanized gangue backfilling mining through appropriate downward contracting and yielding, fully utilizing the carrying capacities of the backfilling gob and the surrounding rock. The characteristics of the high strength and large elastic modulus of the gangue concrete in the late stage can satisfy the roadside support strength required by the GER in the second mining process.

\section{Field Test and Monitoring}

4.1. Mining Geological Conditions. The test mine is in the Shandong Province of China. The ground elevation of the test zone is +32.93 to $+33.08 \mathrm{~m}$; the underground elevation is -642 to $-636 \mathrm{~m}$; the coal seam strike approximates East-West, trending South; and true dip is at $0^{\circ}-3^{\circ}$. The main mining coal seam is seam $3_{\text {lower }}$, coefficient of hardness $f=1-2$, and thickness is at $3.08-4.10 \mathrm{~m}$. Seam $3_{\text {lower }}$ of the coal floor consists of mudstone and siltstone, and Seam $3_{\text {lower }}$ of the coal roof consists of mudstone and siltstone. The hardness coefficient of the mudstone and siltstone $f=4-6$. The advancing speed of the working face was $3 \mathrm{~m}$ per day, and the gob backfilling ratio was designed as $100 \%$. The strata geological log is as shown in Figure 11.

4.2. Roadside Support Design. The width of the RSB is $2 \mathrm{~m}$, and the height is $3.6 \mathrm{~m}$. Crushed continuously graded native gangues at $n=0.6$ were used as aggregate to prepare concrete of $50 \%$ aggregate content. Cement grade is p.c32.5, and water-cement ratio is 0.60 . Flexible cushion at height of $200 \mathrm{~mm}$ is arranged at the upper part of the gangue concrete for roof contact (Figure 12). 
4.3. Field Monitoring. A safe RSB material should meet the following three requirements according to different mining geological conditions.

First of all, the strength of RSB should be greater than roof load at its location. Evaluation criterion of RSB stability is whether the RSB material breaks down in the process of loading and unloading caused by roof movement.

Secondly, shrinkage should be larger than the fieldmeasured deformation of basic roof. Ability of RSB to adapt to the deformation of basic roof can make full use of the bearing capacity of surrounding rock, reducing the roof load on RSB. This is an effective way to ensure that its strength is greater than the roof load.

Thirdly, there is no mutation in the postpeak strength. This means that the material can ensure that the global impact damage will not occur to RSB even if there is local high stress at the gob side. The local slow destruction can be repaired by means of reinforcement, which ensures the safety of RSB.

To analyze the effect of the roadside support, monitoring stations are arranged in the roadway to record the vertical stress and converging deformation during advancement of the working face, as shown in Figure 13.

During backfill GER, the compressive strengths of the roadside support material of various ages satisfy the onsite construction requirement, the max vertical stress in RSB is 3.8 $\mathrm{MPa}$, and the strength safety coefficient is

$$
K=\frac{\sigma_{0}}{\sigma_{\max }}=1.32,
$$

where $K$ is the strength safety coefficient of the gangue concrete material, $\sigma_{0}$ is the average compressive strength of the concrete used in the construction, and $\sigma_{\max }$ is the max vertical stress in RSB, that is, the max workload.

During advancement of the working face, the roof-floor displacement of the roadway was larger than the two-side displacement. The maximum roof-floor displacement was $112 \mathrm{~mm}$, and the maximum two-side displacement was $71 \mathrm{~mm}$. The roadway using gangue cement as RSB material satisfies the design and application requirements.

\section{Conclusions}

Based on the current experimental research and field measurements, the following can be concluded:

(1) The most effective way to adjust the strength of gangue concrete is to change the water-cement ratio of the cementing material. For a fixed gangue content, with the raising of the water-cement ratio, the strength of gangue concrete demonstrates a nonlinear decreasing trend. The water-cement ratio within the range of $0.46-0.60$ has the most significant regulation effect on the strength of the gangue concrete.

(2) Mixing concrete with a certain amount of coal gangue as the aggregate has an important effect on the destruction mode and the postpeak carrying characteristics of the concrete. In the postpeak stage, the stress demonstrates a decreasing trend with an increase of the strain, the process of the crack development is relatively slow, and the gangue concrete has a certain postpeak carrying capacity.

(3) Notwithstanding the water-cement ratio, the compressive strength of the gangue concrete demonstrates an increasing trend with age. With the addition of the gangue aggregate, the concrete's hydration and hardening processes are significantly accelerated. At the age of 14 days, the stiffness and strength of the gangue concrete essentially stabilize.

(4) Based on the laboratory test results and the law of underground pressure, industrial tests were carried out at the working face of gob-backfilled GER. The monitoring results demonstrate that with a rational proportion design, the use of gangue concrete as a RSB material can meet the design and application requirements of the GER. The feasibility and rationality of gangue concrete as a RSB material for the GER were proved. A RSB material featuring high safety, high waste utilization rate, fast construction speed, and low costs was provided, guaranteeing the RSB stability for the GER.

\section{Conflicts of Interest}

The authors declare that they have no conflicts of interest.

\section{Acknowledgments}

This work is supported by the National Natural Science Foundation of China (nos. 51323004, 51674250, 51574228, and 51074163), Major Program of National Natural Science Foundation of China (no. 50834005, 51734009), the Graduate Innovation Fund Project of Jiangsu Province (no. CXZZ13_0924), and Open Fund of State Key Laboratory for Geomechanics and Deep Underground Engineering (SKLGDUEK1409). The authors sincerely acknowledge the former researchers for their excellent works, which greatly assisted our academic study.

\section{References}

[1] P. Gong, Z. Ma, R. R. Zhang, X. Ni, F. Liu, and Z. Huang, "Surrounding rock deformation mechanism and control technology for gob-side entry retaining with fully mechanized gangue backfilling mining: a case study," Shock and Vibration, vol. 2017, Article ID 6085941, 15 pages, 2017.

[2] H. Yang, S. Cao, Y. Li, C. Sun, and P. Guo, "Soft roof failure mechanism and supporting method for gob-side entry retaining," Minerals, vol. 5, no. 4, pp. 707-722, 2015.

[3] H. Li, D. Jiang, and D. Li, "Analysis of ground pressure and roof movement in fully-mechanized top coal caving with large mining height in ultra-thick seam," Journal of China Coal Society, vol. 39, no. 10, pp. 1956-1960, 2014.

[4] H. Yang, S. Cao, S. Wang, Y. Fan, S. Wang, and X. Chen, "Adaptation assessment of gob-side entry retaining based on geological factors," Engineering Geology, vol. 209, pp. 143-151, 2016. 
[5] S. Xie, G. Zhang, S. He et al., "Surrounding rock control mechanism and its application of gob-side retaining entry in deep backfilling with large mining height," Journal of China Coal Society, vol. 39, no. 12, pp. 2362-2368, 2014.

[6] D. Zhang, X. Miao, and X. Mao, "Simulation on roof activities of gob-side entry retaining in fully-mechanized top-coal caving faces," Journal of China University of Mining \& Technology, vol. 30, no. 3, pp. 47-50, 2001.

[7] C. Han, N. Zhang, G. Li, B. Li, and H. Wu, "Stability analysis of compound bearing structure of gob-side entry retaining with large mining height," Chinese Journal of Geotechnical Engineering, vol. 36, no. 5, pp. 969-976, 2014.

[8] Y. Li and X. Hua, "Mechanical analysis of stability of key blocks of overlying strata for gob-side entry retaining and calculating width of roadside backfill," Rock and Soil Mechanics, vol. 33, no. 4, pp. 1134-1140, 2012.

[9] Z. Ma, R. Gu, Z. Huang, G. Peng, L. Zhang, and D. Ma, "Experimental study on creep behavior of saturated disaggregated sandstone," International Journal of Rock Mechanics \& Mining Sciences, vol. 66, no. 1, pp. 76-83, 2014.

[10] X. Zhu, G. Guo, and Q. Fang, "Coupled discrete elementfinite difference method for analyzing subsidence control in fully mechanized solid backfilling mining," Environmental Earth Sciences, vol. 75, no. 8, pp. 1-12, 2016.

[11] G. Guo, W. Feng, J. Zha, Y. Liu, and Q. Wang, "Subsidence control and farmland conservation by solid backfilling mining technology," Transactions of Nonferrous Metals Society of China, vol. 21, no. S3, pp. 665-669, 2011.

[12] G. Li, S. Cao, Y. Li, and Z. Zhang, "Load bearing and deformation characteristics of granular spoils under unconfined compressive loading for coal mine backfill," Advances in Materials Science \& Engineering, vol. 2016, Article ID 8530574, 11 pages, 2016.

[13] F. W. Solesbury, "Coal waste in civil engineering works: 2 case histories from South Africa," in Advances in Mining Science \& Technology, Elsevier, Vol. 1987pp. 207-218, Elsevier, Amsterdam, Netherlands, 1987.

[14] W. Yin, Z. Chen, K. Quan, and X. Mei, "Strata behavior at fully-mechanized coal mining and solid backfilling face," SpringerPlus, vol. 5, no. 1, pp. 1-12, 2016.

[15] X. Zhu, G. Guo, J. Zha, T. Chen, Q. Fang, and X. Yang, "Surface dynamic subsidence prediction model of solid backfill mining," Environmental Earth Sciences, vol. 75, no. 12, pp. 1-9, 2016.

[16] D. Wu, B. Yang, and Y. Liu, "Transportability and pressure drop of fresh cemented coal gangue-fly ash backfill slurry in pipe loop," Powder Technology, vol. 284, pp. 218-224, 2015.

[17] M. Rezaei, M. F. Hossaini, and A. Majdi, "Determination of longwall mining-induced stress using the strain energy method," Rock Mechanics and Rock Engineering, vol. 48, no. 6 , pp. 2421-2433, 2015.

[18] J. Bai, H. Zhou, C. Hou, X. Tu, and D. Yue, "Development of support technology beside roadway in goal-side entry retaining for next sublevel," Journal of China University of Mining \& Technology, vol. 33, no. 2, pp. 59-62, 2004.

[19] X. He and L. Song, "Status and future tasks of coal mining safety in China," Safety Science, vol. 50, no. 4, pp. 894-898, 2012.

[20] J. Ning, J. Wang, T. Bu, S. Hu, and X. Liu, “An innovative support structure for gob-side entry retention in steep coal seam mining," Minerals, vol. 7, no. 5, p. 75, 2017.

[21] H. Wang, D. Zhang, and L. Liu et al., Stabilization of gob-side entry with an artificial side for sustaining mining work," Sustainability, vol. 8, no. 7, p. 627, 2016.
[22] X. Querol, M. Izquierdo, E. Monfort et al., "Environmental characterization of burnt coal gangue banks at Yangquan, Shanxi Province, China," International Journal of Coal Geology, vol. 75, no. 2, pp. 93-104, 2008.

[23] C. Zhou, G. Liu, Z. Yan, T. Fang, and R. Wang, "Transformation behavior of mineral composition and trace elements during coal gangue combustion," Fuel, vol. 97, no. 2, pp. 644-650, 2012.

[24] C. Zhou, G. Liu, S. Wu, and P. K. Lam, "The environmental characteristics of usage of coal gangue in bricking-making: a case study at Huainan, China," Chemosphere, vol. 95, no. 1, pp. 274-280, 2014.

[25] J. Wang, Q. Qin, S. Hu, and K. Wu, “A concrete material with waste coal gangue and fly ash used for farmland drainage in high groundwater level areas," Journal of Cleaner Production, vol. 112, pp. 631-638, 2015.

[26] G. Li, C. Fang, X. Zhao, Y. An, and Y. Liu, "Cyclic behavior of rebar-penetrated connection between gangue concrete filled steel tubular column and reinforced gangue concrete beam," Advanced Steel Construction, vol. 11, no. 1, pp. 54-72, 2015.

[27] D. Wu, S. Cai, and Y. Liu, "Effects of binder on suction in cemented gangue backfill," Magazine of Concrete Research, vol. 68 , no. 12 , pp. 1-11, 2015.

[28] S. Walker, D. L. Bloem, R. D. Gaynor, and J. E. Gray, "Relationships of concrete strength to maximum size aggregate," Highway Research Board, Proceedings of the Annual Meeting, vol. 38, pp. 367-385, 1959. 


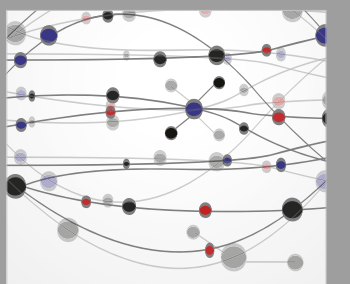

The Scientific World Journal
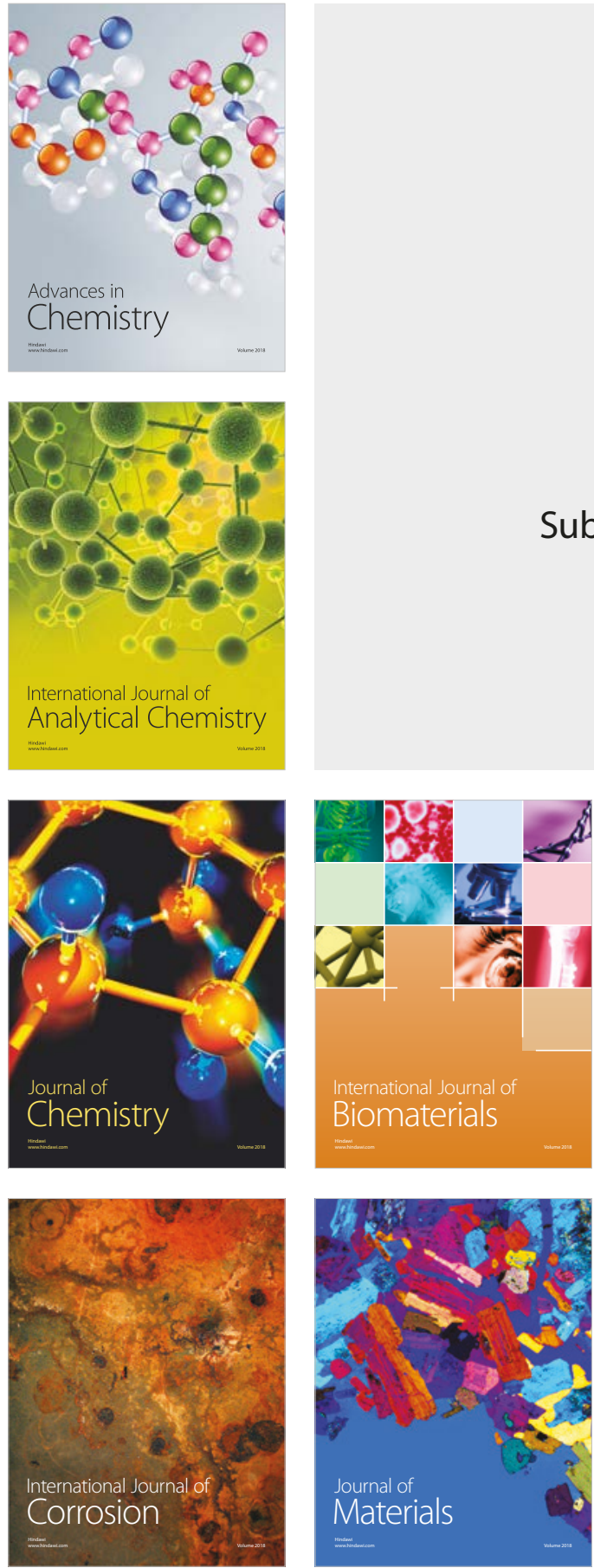

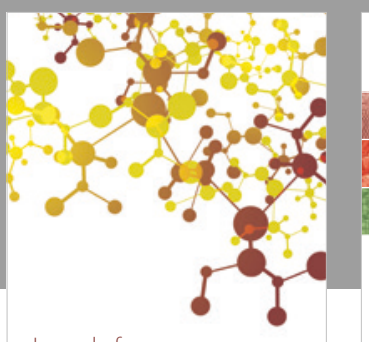

Journal of

Applied Chemistry
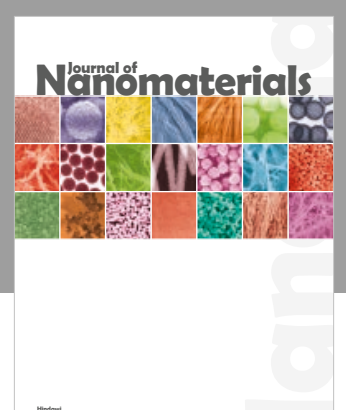

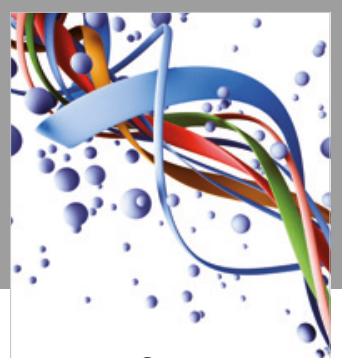

Scientifica

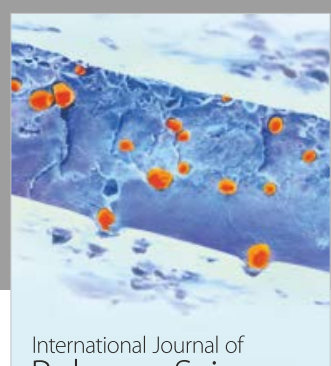

Polymer Science

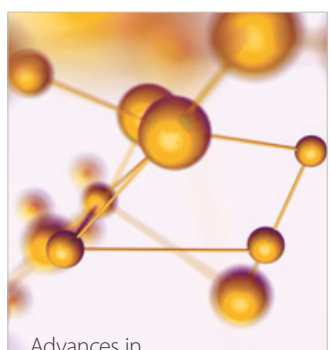

Physical Chemistry
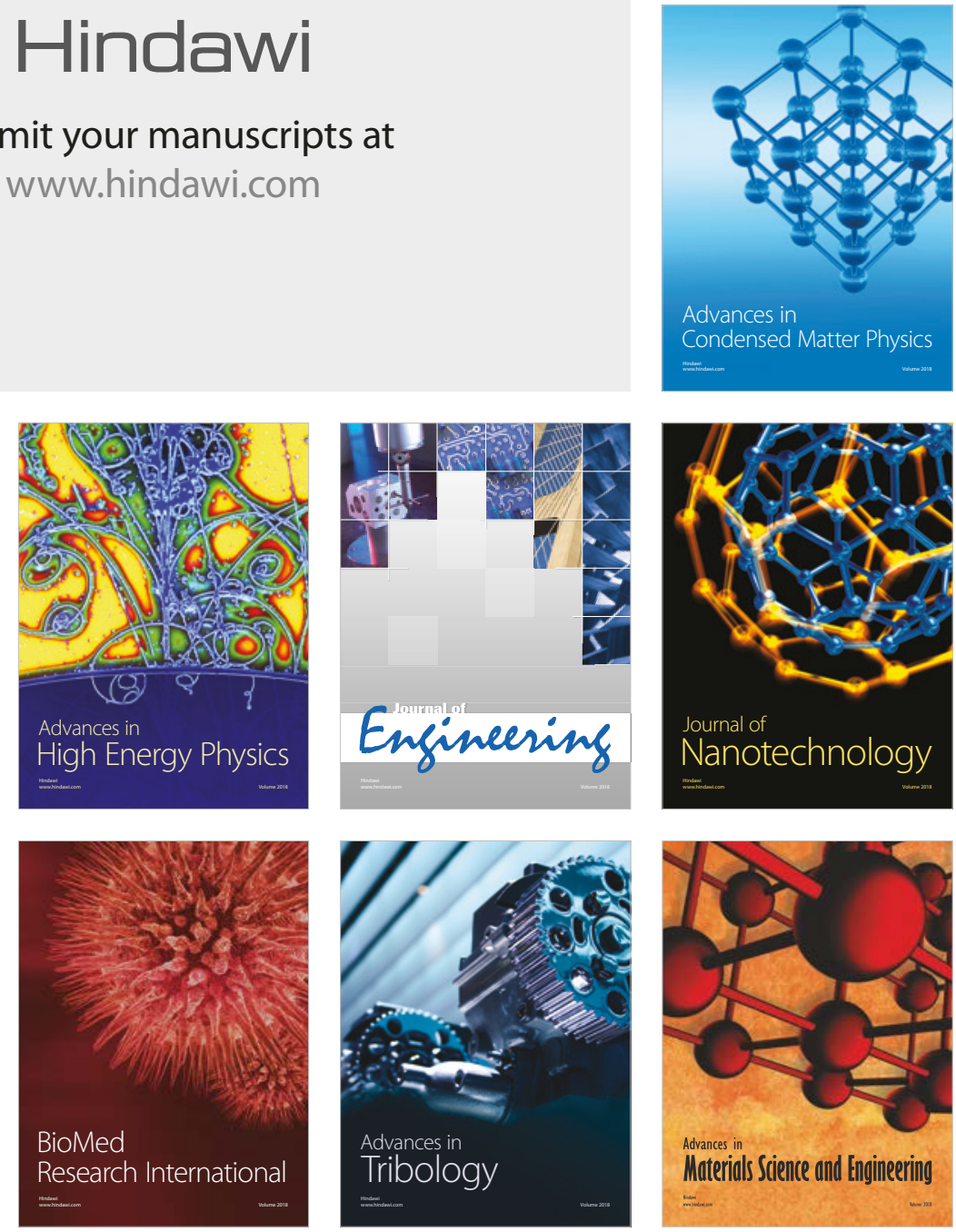